\title{
Opportunistic food consumption in relation to childhood and adult food insecurity: An exploratory correlational study
}

\author{
Daniel Nettle ${ }^{1 *}$, Mona Joly ${ }^{1,2}$, Eleanor Broadbent ${ }^{3}$, Chloe Smith $^{3}$, Ellie Tittle ${ }^{3}$, Melissa \\ Bateson ${ }^{1}$ \\ 1. Centre for Behaviour \& Evolution and Institute of Neuroscience, Newcastle University, \\ Newcastle, UK \\ 2. École Normale Supérieure, 45 rue d'Ulm, Paris, France \\ 3. School of Psychology, Newcastle University, Newcastle, UK
}

* To whom correspondence should be addressed: daniel.nettle@ncl.ac.uk

In press, Appetite, July 2018

\begin{abstract}
Food insecurity is associated with high body weight for women but not men in affluent Western societies. However, it is not currently known what behavioural or psychological mechanisms drive this association. Moreover, it is also unknown whether only current experience of food insecurity in adulthood is important, or there are lasting effects of childhood experience. We carried out a mock 'taste test' where 126 adult volunteers had the opportunity to consume and rate energy-dense snack foods. Current food insecurity was measured using the standard USDA measure, and in addition, we used a novel measure that also captures childhood experience of food insecurity. As well as the expected genderspecific association between current food insecurity and body weight, we found some evidence for associations between food insecurity and calorie consumption in the taste test, and liking of one of the foods, chocolate. However, associations between current food insecurity and the outcomes were moderated by childhood experience of food insecurity, with greater childhood food insecurity enhancing the positive effect of current food insecurity on body weight, but attenuating the positive effect of food insecurity on calorie consumption and liking for chocolate. These findings are exploratory, but they suggest that any effects of food insecurity in adulthood on eating and the hedonic value of foods may be moderated by childhood experience.
\end{abstract}

Keywords: food insecurity, insurance hypothesis, developmental programming, obesity, liking, food motivation, calorie consumption 


\section{Introduction}

Food insecurity $(\mathrm{FI})$, defined as the limited or uncertain ability to acquire nutritionally adequate and safe food in socially acceptable ways (Anderson, 1990), is associated with high body weight for women but not men in affluent Western societies. This pattern has been found in a number of well-powered epidemiological studies (Adams, Grummer-strawn, \& Chavez, 2003; Hanson, Sobal, \& Frongillo, 2007; Martin-Fernandez, Caillavet, Lhuissier, \& Chauvin, 2014; e.g. Townsend, Peerson, Love, Achterberg, \& Murphy, 2001), and is confirmed by a large meta-analysis (Nettle, Andrews, \& Bateson, 2017). The association survives control for socioeconomic status, although socioeconomic status does tend to be correlated with FI (Gundersen, Kreider, \& Pepper, 2011). Although the relationship between FI and high body weight is often described as 'paradoxical' (Crawford \& Webb, 2011; Dinour, Bergen, \& Yeh, 2007; Tanumihardjo et al., 2007), Nettle et al. (2017) argue that increased body weight represents the expected biological response to an insecure food supply. Foodinsecure organisms must insure themselves against periods of shortfall with extra consumption and energy storage when food is easily available. This principle is supported by behavioural-ecological models (Higginson, McNamara, \& Houston, 2016; Lima, 1986); and in non-human animals, experimentally imposing food insecurity leads to increased consumption and/or weight gain (Ekman \& Hake, 1990; Li, Cope, Johnson, Smith, \& Nagy, 2010; Wilson \& Cantor, 1987; Witter \& Swaddle, 1995). Thus, Nettle et al. (2017) argue that the association between $\mathrm{FI}$ and high body weight may be causal: humans_human females at least-may possess psychological mechanisms that respond to experiences of FI by motivating them to consume more than they expend when the opportunity is available.

It follows from the energy balance equation for weight gain that there are two (non-mutuallyexclusive) ways an association between $\mathrm{FI}$ and high body weight could come about. Either food-insecure individuals could have higher food intake when eating opportunities present themselves; and/or food-insecure individuals could have lower energy expenditure. Despite the large literature on FI and body weight in humans, the direct evidence for higher caloric intake in food-insecure individuals in sparse. One early study demonstrated poorer diet quality associated with FI, but without measuring caloric intake (Kendall, Olson, \& Frongillo, 1996). A more recent study found that children in food insecure households consumed more calories overall, and more added sugars in particular, than children in food-secure households (Sharkey, Nalty, Johnson, \& Dean, 2012). However, since the parents rather than the children will have dictated the available foods, this gives only indirect insight into how experience of food insecurity alters individual food motivation.

Thus, it remains to be established that food-insecure individuals consume more calories than non-food-insecure individuals do when opportunities present themselves. If they do, it may be because $\mathrm{Fl}$ is associated with higher hedonic value of energy-dense foods, since high hedonic value of energy-dense foods is related to weight gain (Finlayson, King, \& Blundell, 2007). The present study aimed to explore these issues, by presenting adult volunteers with a standardized opportunity to freely consume energy-dense snack foods, as well as rate how much they liked them, under the guise of a mock 'taste test'. Participants drank a preload of a sugary drink 10 minutes prior to the taste test. This preloading procedure has been used in previous studies to equalize cues of internal energetic need (Hill, Prokosch, DelPriore, Griskevicius, \& Kramer, 2016; Wang \& Dvorak, 2010). Thus, any excess calorie consumption by food-insecure individuals should indicate that such individuals are prone to consume more 
even in the absence of cues of energetic need, not just that they were hungrier when they came to the session.

To measure FI, we administered the standard USDA FI questionnaire (Bickel, Nord, Price, Hamilton, Cook, et al., 2000), as well as developing novel questionnaire measures of our own. The motivations for the novel measures were the following. The USDA questionnaire measures only current FI (i.e. FI in adulthood when used with adults). However, there are suggestions in the literature that $\mathrm{FI}$ or related deprivation experienced during childhood have a developmental programming effect on adult food-related behaviour (Hill et al., 2016; Olson, Bove, \& Miller, 2007). That is, having experienced childhood FI may be related to adult food motivation, even after controlling for current FI. Our novel questionnaire separately enquires about experiences of $\mathrm{Fl}$ in the past year; and when the respondent was a child. It thus yields two separate two scores henceforth described as AFI (adult food insecurity) and CFI (childhood food insecurity). It was not possible to simply reuse the USDA questions but change their timeframe to childhood in order to capture childhood experience of $\mathrm{FI}$. The USDA questions specifically probe FI due to lack of financial resources. People may not know or remember the reasons for their experiences in childhood, though; only that meals were irregular or that they were sometimes hungry. More generally, if there are evolved psychological mechanisms that respond to cues or experiences of insecurity, there is no reason to expect they would only be sensitive to insecurity whose cause is financial. The psychological response to food unavailability appears to be similar whatever its cause (Polivy, 1996). Thus, our new measures designed to assess any experience of FI, whatever its source, in the current time or in childhood respectively.

Our main outcome measures were: participant BMI; consumption of the foods in the taste test; and rated liking of the foods in the taste test. Our predictor variables were current $\mathrm{FI}$ (either USDA score or AFI, both sets of analyses are presented); childhood $\mathrm{FI}(\mathrm{CFI}$ ), and gender. Interactions between gender and the FI measures were included in all analyses. Our predictions, based on the Fl-body weight literature, are that FI will be associated with higher BMI, higher consumption and greater liking of the foods for women, but not for men. Hence we predict an interaction between gender and current $\mathrm{FI}$, which, taking women as the reference category, will have a negative sign. We consider the analyses testing these predictions to be confirmatory: the BMI prediction derives from the known associations of FI with body weight in women and men, and the consumption and liking predictions follow directly from the hypothesis that greater consumption and greater hedonic value of food are mechanisms behind the gender-specific association of $\mathrm{FI}$ and body weight.

Based on the arguments for developmental programming effects in the literature, we expected that childhood FI might explain variation in BMI, consumption, and liking of the foods, above and beyond that explained by adult FI alone. We considered both main effects of childhood $\mathrm{FI}$, interactions with gender, and interactions between current $\mathrm{FI}$ and childhood $\mathrm{FI}$. The mode of operation of developmental programming in some cases appears to be sensitization of individuals to relevant features of their adult situation (see for example Griskevicius, Tybur, Delton, \& Robertson, 2011). This can lead to non-additive interactions between childhood experience and adult context in predicting behaviour. We consider the analyses involving childhood FI to be exploratory, since we have no clear basis for predicting whether there will be additive effects or interactions, or what form interactions might take. 


\section{Materials \& Methods}

\section{Ethics}

The study was approved by the Faculty of Medical Sciences ethics committee of Newcastle University, approval no. 1400/15594/2017. All participants provided written informed consent.

\section{Participants}

We recruited an opportunity sample of 126 participants (42 male, 84 female, see table 1 for sample characteristics) through research participation registers held at Newcastle University. Ninety-four participants were undergraduate students, 8 were post-graduate students, and the remaining 24 worked at the university or were members of the local community. Participants were requested not to take part if they had any intolerances or allergies to egg, gluten, milk or soya.

\section{Procedure}

Participants were instructed not to eat anything for 90 minutes before the session.

Participants were tested individually. They were met by a researcher and led into a laboratory room, where they would be screened from the experimenter's view with curtains. After instruction and filling in a consent form, the participants were invited to drink the content of two plastic cups containing $75 \mathrm{ml}$ of Coca-Cola $(42 \mathrm{kcal} / 100 \mathrm{ml}$ ) and $75 \mathrm{ml}$ of Pepsi (44 $\mathrm{kcal} / 100 \mathrm{ml}$ ). All participants did so. Participants then completed a 10-min filler task (watching video commercials of the two brands and answering questions about the drinks and the advertisements) that should allow time for changes in blood glucose level to occur (Wang \& Dvorak, 2010). We then measured current subjective hunger (participants bisected a horizontal line with a mark, position subsequently measured in $\mathrm{mm}$ ), hours since last meal, and the content of the last meal, as well as a number of demographic questions. Once these measures were complete, height and weight were measured using a stadiometer (measured in inches, precision 1/8 inch, and converted to $\mathrm{cm}$ ) and digital scales (precision $0.1 \mathrm{~kg}$ ). BMI was calculated from these values.

Participants were then presented with pre-weighed standard plates of three food products: salted popcorn ( $10 \mathrm{~g}$ on plate; $527 \mathrm{kcal} / 100 \mathrm{~g}$ ), ready salted crisps (potato chips; $19 \mathrm{~g}$ on plate; $533 \mathrm{kcal} / 100 \mathrm{~g}$ ), and squares of milk chocolate ( $68 \mathrm{~g}$ on plate; $534 \mathrm{kcal} / 100 \mathrm{~g}$ ). The three plates were all visible simultaneously. The food amounts were chosen to make the three plates appear similarly full. Participants were instructed to taste each food, complete a number of qualitative questions, and rate their overall liking for the food (5-point Likert scale). On completion of this task, they were notified that they could go on eating as much as they wished, since the leftovers would go to waste. The researcher left them alone to complete the three FI questionnaires (see below), whilst eating more of the foods if they wished. On completion, they summoned the researcher, were thanked and debriefed with the true aim of the study, and escorted out. The remaining amounts of each food were weighed using digital scales (precision $1 \mathrm{~g}$ ), and the amounts consumed converted to calories using nutritional information provided on the packaging. 


\section{Materials}

Participants completed the individual-related items (questions 2, 3, 4, 4a, 8, 8a, 9, 10, 11, 12 and 12a ) from the standard USDA questionnaire (Bickel, Nord, Price, Hamilton, \& Cook, 2000). Cronbach's a was 0.86 for the USDA score. Sixty-seven participants (53\%) had at least one positive response, and hence some symptom of food insecurity. Thirty participants (24\%) had more than two positive responses, and would thus be considered categorically food-insecure by USDA guidelines (Bickel, Nord, Price, Hamilton, Cook, et al., 2000).

Our two novel FI measures, the AFI and CFI, each consisted of the same 20 'yes/no' questions (see Appendix). The items were generated through discussion between the authors of the kinds of experience that would be indicative of $\mathrm{Fl}$, regardless of the cause. The questions balanced those where a 'yes' indicated greater FI and those where a 'no' indicated greater Fl. The score in each case was the number of 'high Fl' responses. The difference between the AFI and CFI was that in the former case, participants were asked to think about the past year, whereas for the latter, the participant was asked to think about the period of their lives up until they were 12 years old. Cronbach's $\alpha$ was 0.83 for AFI and 0.78 for CFI. At the end of each of the two new scales, the participants were asked on a 5-point Likert scale how easy it had been for them to recollect the relevant memories.

\section{Data analysis}

One participant failed to complete the liking ratings, and hence the sample size is one smaller for analyses involving liking $(n=125)$ than other analyses $(n=126)$. The calorie consumptions of each of the three foods were highly positively correlated with one another (all $r s>0.75$ ). Hence, we summed together the three food types and analyse total calories consumed as the consumption outcome variable. Very similar results are obtained using calories of chocolate consumed as the outcome variable (chocolate consumption accounted for more than $95 \%$ of the variation in total calorie consumption). The liking ratings for the three foods were not correlated (all $r s<0.10$ ), and hence are considered separately. Calorie consumption, CFI, USDA score, and BMI all had skewed distributions and were log transformed for analysis. AFI score was used untransformed. For plotting, we have retained variables in their raw state, even where logarithmic transformations are used in the corresponding statistical models.

In preliminary analyses, we first explored the associations between calories consumed, liking of the foods, BMI and current hunger; and the associations of AFI and CFI with one another, with the USDA score, and with current hunger. For the main analyses, we present parallel analyses using the USDA score as the measure of current FI, and using our AFI score.

For each predictor variable, we first fitted general linear models with current FI (either USDA or AFI), gender, and the current FI by gender interaction as the predictors. These basic models, summarised in table 2 , are the simplest direct test of our predictions regarding current FI. To investigate whether CFI had any explanatory value above and beyond current $\mathrm{Fl}$, for outcomes where we had found significant effects involving current $\mathrm{Fl}$, we then compared the basic model to models in which CFI had also been added, in the five possible ways (namely: only main effect of $\mathrm{CFI}$, main effect plus interaction with gender; main effect plus interaction with $\mathrm{AFI}$, main effect plus both 2-way interactions; main effect plus both 2- 
way and 3-way interactions). We retained as our final model that with the lowest AICc value. These models are summarised in table 3.

For the general linear models, FI predictors were standardized and centred to facilitate interpretation of interactions. All analyses were run in R 3.3.3. software (R Core Team, 2016). R scripts and raw data from the study are freely available via the Zenodo repository at: https://doi.org/10.5281/zenodo.1197845.

\section{Results}

Preliminary analyses: Consumption and liking

Caloric consumption of the foods during the taste test was highly variable across participants (see table 1 for descriptive statistics). Calorie consumption was not significantly related to self-reported current hunger $\left(r_{124}=0.11, p=0.23\right)$, and was weakly positively correlated with BMI $\left(r_{124}=0.22, p=0.01\right)$. Calorie consumption was not significantly correlated with liking of the foods (all $r s<0.15$ ), and liking of the foods was not significantly correlated with current hunger (all $r s<0.11$ ). Finally, BMI was not significantly correlated with liking of any of the three foods (all $r s<0.08$ ).

\section{Preliminary analyses: Food insecurity}

$\mathrm{AFI}$ and CFI were weakly positively correlated with one another $\left(r_{124}=0.24, p<0.01\right)$. AFI scores were significantly higher than CFI scores (paired t-test : $t_{125}=12.90, p<0.01$; since the two scales involve exactly the same questions with two different reference periods, this comparison is meaningful). CFI produced much smaller variability than AFI (table 1).

Unsurprisingly, participants reported finding it more difficult to recollect the relevant memories for CFI than AFI (CFI: mean 3.81, s.d. 0.71; AFI: mean 4.65, s.d. 0.54; paired ttest: $\left.\mathrm{t}_{124}=-11.78, p<0.01\right)$. The USDA score was significantly positively correlated with both AFI $\left(r_{124}=0.58, p<0.01\right)$ and CFI $\left(r_{124}=0.25, p<0.01\right)$. The stronger correlation with AFI is reassuring, since USDA and AFI are both intended to measure current FI. Neither AFI, CFI, nor USDA score were significantly correlated with current hunger $\left(A F I: r_{124}=-0.13, p=0.16\right.$; CFI: $r_{124}=0.09, p=0.32 ;$ USDA: $r_{124}=-0.09, p=0.33$ ). 
Table 1. Descriptive statistics for the main study variables

\begin{tabular}{|l|l|l|l|l|}
\hline Variable & Median & Mean & $\begin{array}{l}\text { Standard } \\
\text { deviation }\end{array}$ & Range \\
\hline Age & 20 & 24.50 & 10.98 & $18-72$ \\
\hline USDA Score & 1 & 1.68 & 2.40 & $0-10$ \\
\hline AFI & 8 & 8.62 & 4.29 & $1-19$ \\
\hline CFI & 2 & 3.20 & 3.01 & $0-19$ \\
\hline Current hunger & 55.10 & 50.92 & 22.36 & $5.21-100$ \\
\hline BMl & 23.13 & 23.45 & 3.90 & $15.43-40.37$ \\
\hline Calories consumed & 93.97 & 154.25 & 151.77 & $5.34-562.50$ \\
\hline Liking chocolate & 4 & 4.14 & 0.90 & $1-5$ \\
\hline Liking crisps & 4 & 3.71 & 0.81 & $1-5$ \\
\hline Liking popcorn & 3 & 3.10 & 1.06 & $1-5$ \\
\hline
\end{tabular}

Basic models with current $\mathrm{Fl}$ and gender as predictors

Table 2 summarizes the basic models in which the outcome variables were predicted by current FI, gender, and their interaction. Using the USDA score as the current FI measure, there was a significant main effect of current $\mathrm{FI}$ on BMI, as well as a significant interaction between current $\mathrm{FI}$ and gender. The $\mathrm{FI}$ associations took the predicted form: a positive association in women, absent in men (figure 1; simple slopes: 0.05 for women, -0.01 for men). Using the AFI measure instead of USDA, the associations were in the same direction (simple slopes: 0.03 for women, -0.01 for men), but not significant.

For calorie consumption, using USDA, only the main effect of gender was significant (men consumed more than women; means (s.d.): 230.16 kcals (164.60) versus 116.29 (130.11)). Using AFI, there was, as well as the significant main effect of gender, a significant interaction between current $\mathrm{FI}$ and gender. As predicted, this was because of a more positive slope in women than men. However, the pattern was as much due to a negative relationship between current $\mathrm{FI}$ and consumption in men, as a positive relationship in women (figure 2; simple slopes: 0.18 for women and -0.21 for men).

For liking for chocolate, results were almost identical using USDA and using AFI: a significant main effect of current $\mathrm{Fl}$, with more food-insecure individuals liking chocolate more $(B=0.02$; figure 3), but the main effect of gender and the gender by current FI interaction nonsignificant (though for both measures, the simple slopes were steeper for women than men: USDA: 0.22 for women, -0.02 for men; AFI: 0.23 for women, -0.03 for men). For liking of the other two foods, there were no significant predictors in the models. 
Table 2. Summary of statistical models for each study outcome with current FI, gender, and their interaction as the predictors. For gender, female is the reference category, and so parameter estimates for gender represent male deviations from the female outcome.

\begin{tabular}{|c|c|c|c|c|c|c|c|}
\hline & & \multicolumn{3}{|c|}{ USDA as the current FI measure } & \multicolumn{3}{|c|}{$\mathrm{AFI}$ as the current FI measure } \\
\hline $\begin{array}{l}\text { Outcome } \\
\text { variable }\end{array}$ & Predictor & B (s.e.) & $\mathrm{t}$ & $p$-value & B (s.e.) & $\mathrm{t}$ & p-value \\
\hline \multirow[t]{3}{*}{ BMI } & Current FI & $0.05(0.02)$ & 3.10 & $0.002^{*}$ & $0.03(0.02)$ & 1.89 & 0.06 \\
\hline & Gender & $0.04(0.03)$ & 1.22 & 0.22 & $0.04(0.03)$ & 1.20 & 0.23 \\
\hline & $\begin{array}{l}\text { Current FI } \\
{ }^{*} \text { Gender }\end{array}$ & $-0.06(0.03)$ & -2.15 & $0.03^{*}$ & $\begin{array}{l}-0.04 \\
(0.03)\end{array}$ & -1.33 & 0.19 \\
\hline \multirow{3}{*}{$\begin{array}{l}\text { Calorie } \\
\text { consumption }\end{array}$} & Current FI & $0.05(0.11)$ & 0.43 & 0.70 & $0.18(0.10)$ & 1.72 & 0.09 \\
\hline & Gender & $0.80(0.18)$ & 4.41 & $<0.001^{*}$ & $0.79(0.18)$ & 4.36 & $<0.001^{*}$ \\
\hline & $\begin{array}{l}\text { Current FI } \\
{ }^{*} \text { Gender }\end{array}$ & $-0.07(0.18)$ & -0.44 & 0.66 & $\begin{array}{l}-0.38 \\
(0.18)\end{array}$ & -2.09 & $0.03^{*}$ \\
\hline \multirow{3}{*}{$\begin{array}{l}\text { Liking for } \\
\text { chocolate }\end{array}$} & Current FI & $0.23(0.10)$ & 2.29 & $0.02^{*}$ & $0.23(0.10)$ & 2.32 & $0.02^{*}$ \\
\hline & Gender & $-0.10(0.17)$ & -0.61 & 0.54 & $\begin{array}{l}-0.10 \\
(0.17)\end{array}$ & -0.56 & 0.57 \\
\hline & $\begin{array}{l}\text { Current FI } \\
{ }^{*} \text { Gender }\end{array}$ & $-0.25(0.17)$ & -1.47 & 0.15 & $\begin{array}{l}-0.26 \\
(0.17)\end{array}$ & -1.47 & 0.14 \\
\hline \multirow{3}{*}{$\begin{array}{l}\text { Liking for } \\
\text { popcorn }\end{array}$} & Current FI & $-0.01(0.12)$ & -0.10 & 0.92 & $0.00(0.12)$ & 0.01 & 0.99 \\
\hline & Gender & $-0.11(0.20)$ & -0.56 & 0.58 & $\begin{array}{l}-0.14 \\
(0.20)\end{array}$ & -0.67 & 0.50 \\
\hline & $\begin{array}{l}\text { Current FI } \\
{ }^{*} \text { Gender }\end{array}$ & $-0.08(0.20)$ & -0.40 & 0.69 & $\begin{array}{l}0.19 \\
(0.21) \\
\end{array}$ & -0.90 & 0.37 \\
\hline \multirow{3}{*}{$\begin{array}{l}\text { Liking for } \\
\text { crisps }\end{array}$} & Current FI & $0.03(0.09)$ & 0.29 & 0.78 & $0.00(0.09)$ & 0.00 & 1.00 \\
\hline & Gender & $-0.15(0.15)$ & -0.96 & 0.34 & $\begin{array}{l}-0.14 \\
(0.16)\end{array}$ & -0.90 & 0.37 \\
\hline & $\begin{array}{l}\text { Current FI } \\
{ }^{*} \text { Gender }\end{array}$ & $-0.20(0.15)$ & -1.29 & 0.20 & $\begin{array}{l}-0.00 \\
(0.15) \\
\end{array}$ & -0.02 & 0.99 \\
\hline
\end{tabular}

${ }^{*} p<0.05$ 


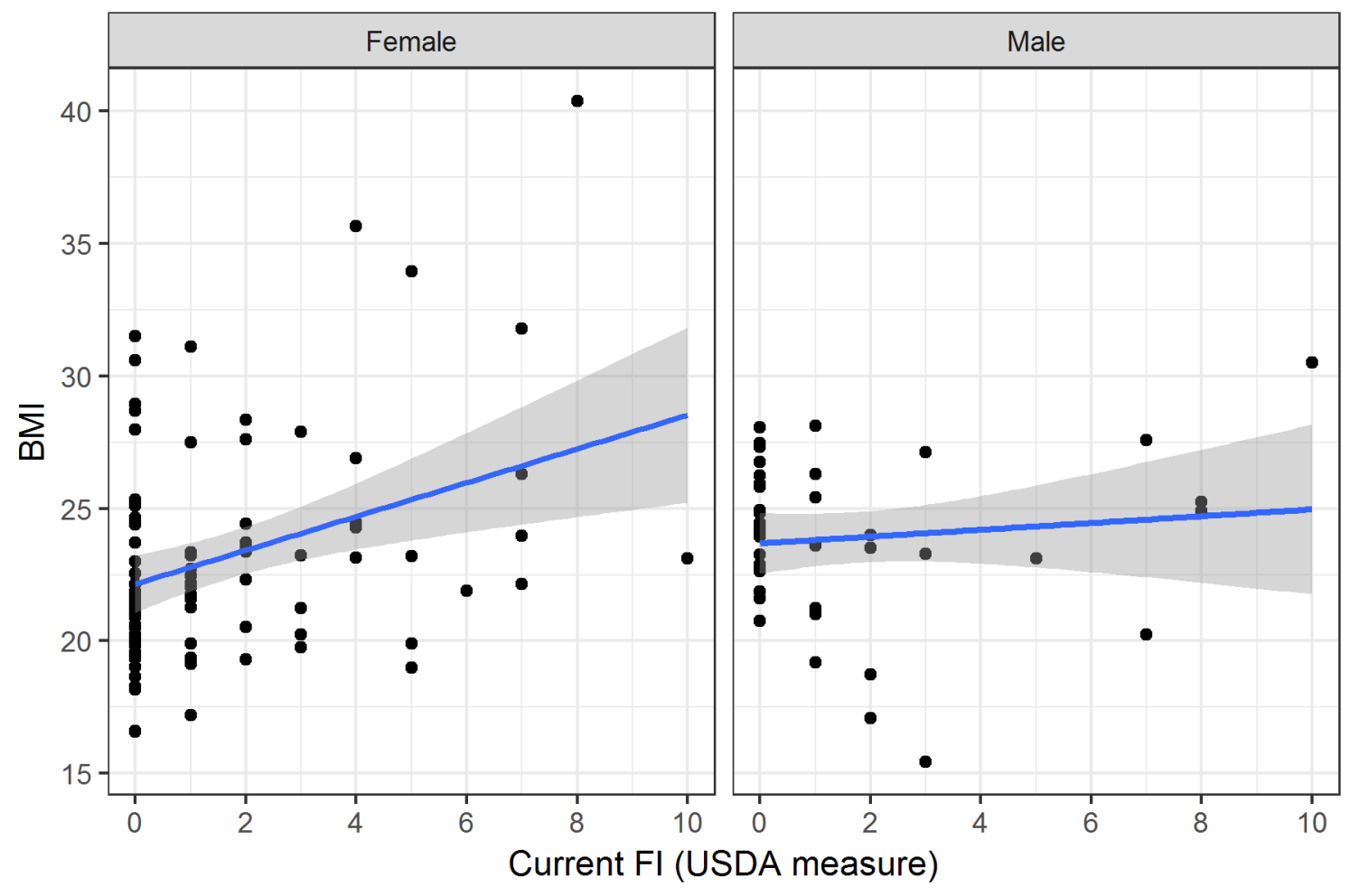

Figure 1. Scatterplot of BMI against current food insecurity (USDA score) for female and male participants. Solid lines represent linear fits through the raw data, with shaded areas representing the $95 \%$ confidence intervals.

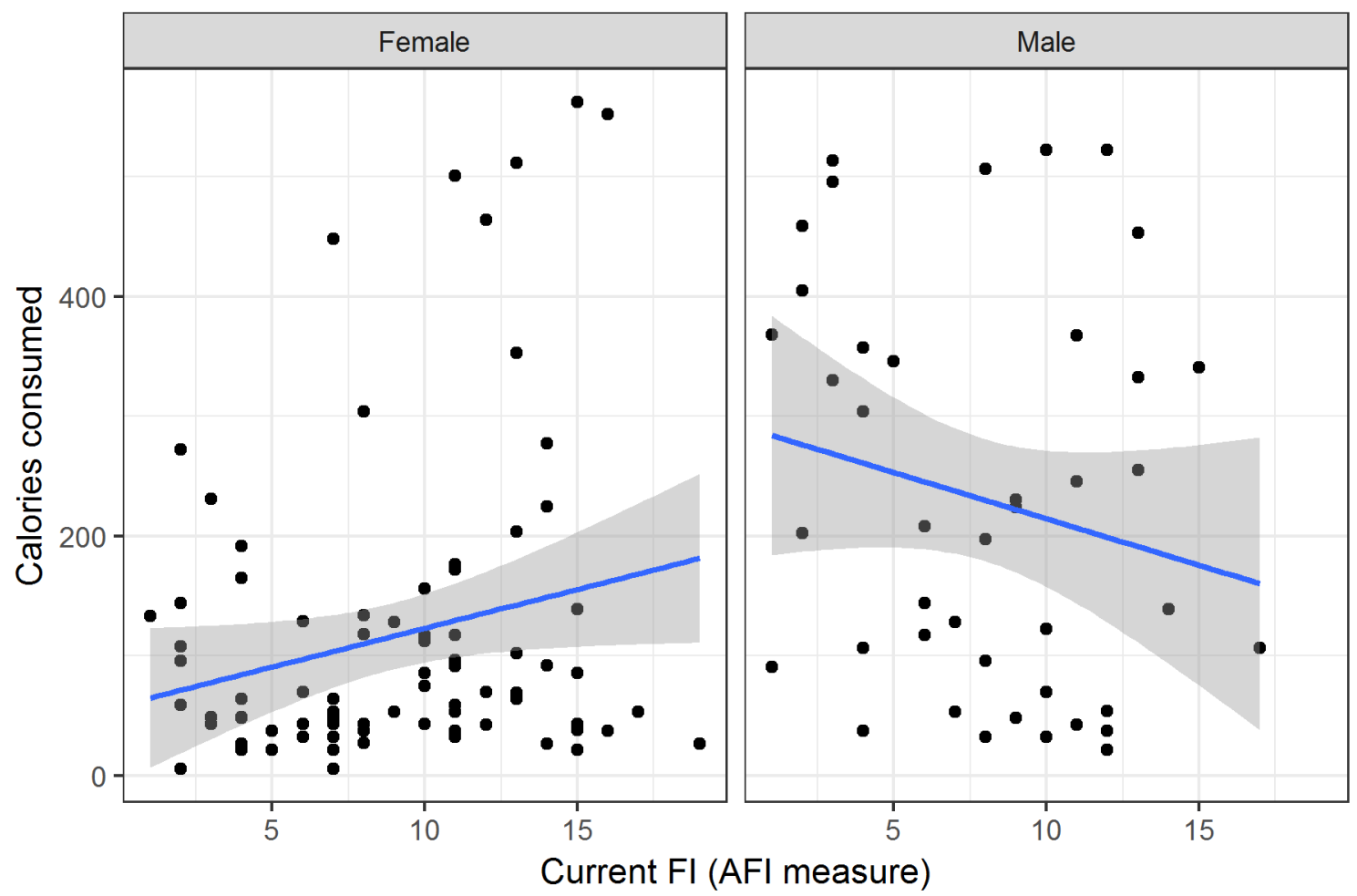

Figure 2. Scatterplots of total calories consumed in the taste test against current food insecurity (AFI measure) for female and male participants. Solid lines represent linear fits through the raw data, with shaded areas representing the $95 \%$ confidence intervals. 


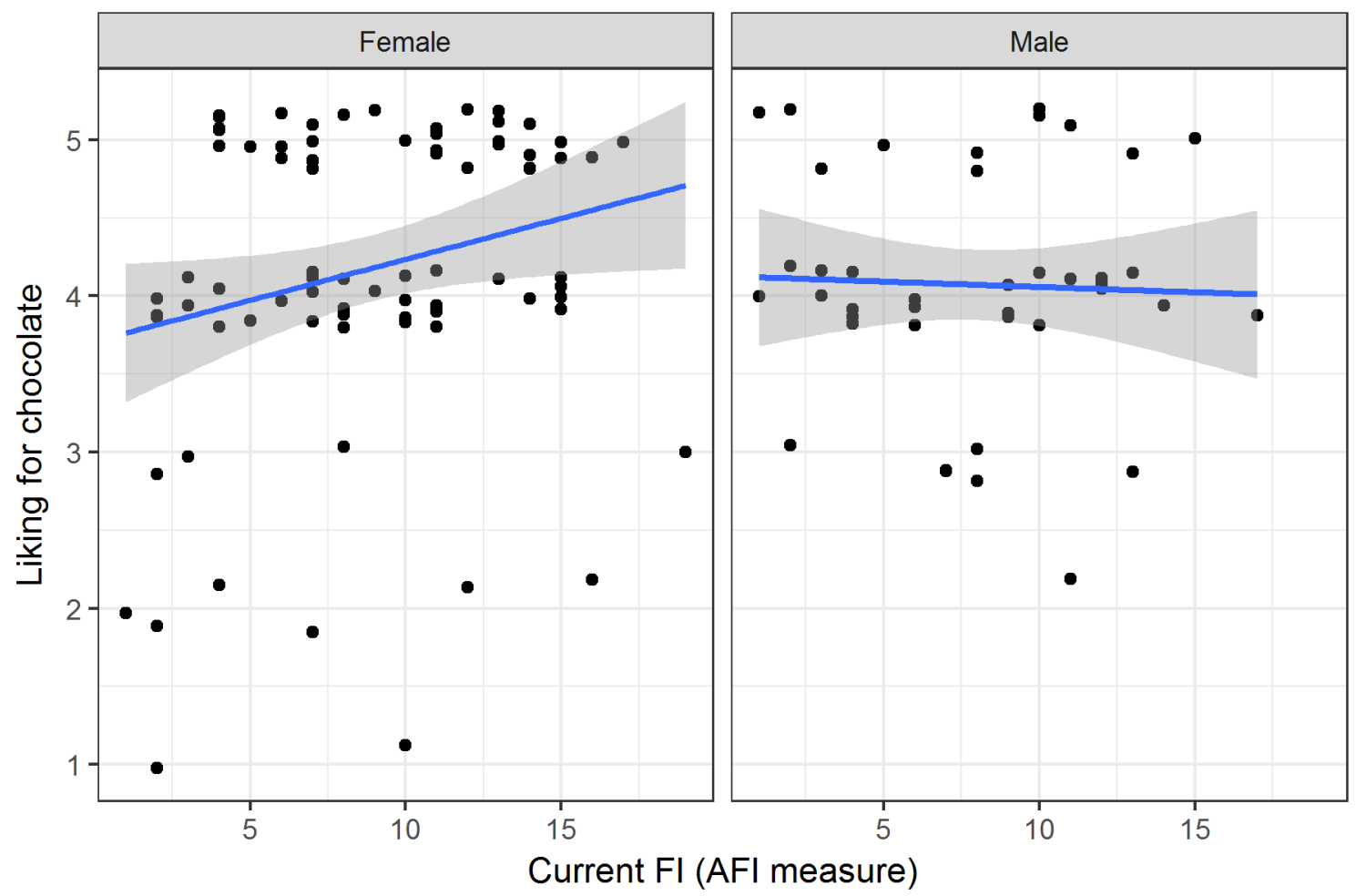

Figure 3. Scatterplot of rated liking for chocolate by current food insecurity, for female and male participants. The AFI measure is shown, but very similar results are obtained using the USDA measure. The AFI by gender interaction is not statistically significant. Points have been jittered slightly in the vertical dimension to avoid over-plotting given the discrete rating values. Solid lines represent linear fits through the raw data, with shaded areas representing the $95 \%$ confidence intervals. 


\section{Adding in childhood FI}

For the three outcomes where there were significant effects involving current $\mathrm{FI}$ for at least one of USDA and AFI, we considered all possible models additionally including CFI and its interactions, retaining the one with the lowest AICc value. Table 3 summarises these models.

For BMI, the best-fitting USDA model (AICc 1.62 units better than the basic model) included $\mathrm{CFI}$ and the interaction between CFI and USDA. The main effect of USDA and its interaction remained significant in this model. Additionally, the interaction between CFI and USDA was significant, with a positive sign. This means that exposure to more childhood FI potentiates the effect of current FI on BMI (simple slopes of BMI on USDA: 0.02 for a woman 1 s.d. below the mean of CFI; 0.09 for a woman 1 s.d. above the mean of CFI). Using AFI instead of USDA, no model involving CFI improved model fit compared to the basic model.

For calories consumed, models involving CFI improved model fit both when using USDA and when using AFI (best model 6.10 AICc units better than basic model using USDA, 1.34 units using AFI). There were some differences between the best-fitting models in the two cases. Using USDA, the main effect of CFI was significant, and there was also a significant threeway interaction between gender, current $\mathrm{FI}$, and CFI. Using AFI, the main effect of CFI was not significant, and the three-way interaction was not included in the model. For both models, though, there was a significant two-way interaction between current $\mathrm{FI}$ and $\mathrm{CFI}$, with a negative sign. This means that, opposite to the BMI case, experiencing more childhood FI attenuates the relationship between current $\mathrm{FI}$ and calories consumed (simple slopes using USDA: 0.23 for a woman 1 s.d. below mean CFI, -0.27 for a woman 1 s.d. above mean CFI; using AFI: 0.30 for a woman 1 s.d. below mean $\mathrm{CFI},-0.05$ for a woman 1 s.d. above mean $\mathrm{CFI}$ ).

For liking for chocolate, models including CFI improved model fit both for USDA and AFI (by 2.10 AICc units for USDA and 6.06 AICc units using AFI). In the USDA model, only a main effect of CFI was included. This effect was significantly negative, indicating that greater childhood FI was associated with less liking for chocolate (the opposite direction to the significant positive association for current FI). The AFI model concurred in including the significant negative association between $\mathrm{CFI}$ and liking, and the significant positive association between current $\mathrm{FI}$ and liking. It additionally included a significant interaction between $\mathrm{CFI}$ and $\mathrm{AFI}$, with a negative sign (i.e. greater $\mathrm{CFI}$ attenuates the positive association between AFI and liking; simple slopes: 0.46 for a woman 1 s.d. below mean CFI, 0.10 for a woman 1 s.d. above mean CFI). 
Table 3. Summary of best-fitting statistical models for each study outcome once childhood FI and all possible interactions are included as predictors in addition to current $\mathrm{FI}$ and gender. For gender, female is the reference category, and so parameter estimates for gender represent male deviations from the female outcome.

\begin{tabular}{|c|c|c|c|c|c|c|c|}
\hline \multirow[b]{2}{*}{$\begin{array}{l}\text { Outcome } \\
\text { variable }\end{array}$} & \multirow[b]{2}{*}{ Predictor } & \multicolumn{3}{|c|}{ USDA as the current FI measure } & \multicolumn{3}{|c|}{$\mathrm{AFI}$ as the current FI measure } \\
\hline & & B (s.e.) & $\mathrm{t}$ & $p$-value & B (s.e.) & $\mathrm{t}$ & $p$-value \\
\hline \multirow[t]{5}{*}{ BMI } & Current FI & $0.06(0.02)$ & 3.29 & $0.001^{*}$ & $0.03(0.02)$ & 1.89 & 0.06 \\
\hline & Gender & $0.04(0.03)$ & 1.29 & 0.21 & $0.04(0.03)$ & 1.20 & 0.23 \\
\hline & Childhood FI & $-0.01(0.01)$ & -0.66 & 0.51 & - & - & - \\
\hline & $\begin{array}{l}\text { Current FI } \\
{ }^{*} \text { Gender }\end{array}$ & $-0.08(0.03)$ & -2.83 & $0.006^{*}$ & $\begin{array}{l}-0.04 \\
(0.03)\end{array}$ & -1.33 & 0.19 \\
\hline & $\begin{array}{l}\text { Current FI * } \\
\text { Childhood FI }\end{array}$ & $0.03(0.01)$ & 2.41 & $0.02^{*}$ & - & - & - \\
\hline \multirow{7}{*}{$\begin{array}{l}\text { Calorie } \\
\text { consumption }\end{array}$} & Current FI & $-0.02(0.11)$ & -0.16 & 0.88 & $0.13(0.11)$ & 1.18 & 0.24 \\
\hline & Gender & $0.61(0.19)$ & 3.21 & $0.002^{*}$ & $0.66(0.19)$ & 3.52 & $0.001^{*}$ \\
\hline & Childhood FI & $0.22(0.11)$ & 2.05 & $0.04^{*}$ & $0.14(0.09)$ & 1.50 & 0.14 \\
\hline & $\begin{array}{l}\text { Current FI } \\
{ }^{*} \text { Gender }\end{array}$ & $-0.23(0.20)$ & -1.15 & 0.25 & $\begin{array}{l}-0.29 \\
(0.18)\end{array}$ & -1.59 & 0.14 \\
\hline & $\begin{array}{l}\text { Childhood FI } \\
{ }^{*} \text { Gender }\end{array}$ & $-0.24(0.19)$ & -1.26 & 0.21 & - & - & - \\
\hline & $\begin{array}{l}\text { Current FI * } \\
\text { Childhood FI }\end{array}$ & $-0.25(0.11)$ & -0.24 & $0.02^{*}$ & $\begin{array}{l}-0.17 \\
(0.09)\end{array}$ & -2.01 & $0.047^{*}$ \\
\hline & $\begin{array}{l}\text { Current FI * } \\
\text { Childhood FI } \\
{ }^{*} \text { Gender }\end{array}$ & $0.57(0.17)$ & 3.42 & $0.001^{*}$ & - & - & - \\
\hline \multirow{4}{*}{$\begin{array}{l}\text { Liking for } \\
\text { chocolate }\end{array}$} & Current FI & $0.27(0.10)$ & 2.70 & $0.01^{*}$ & $0.28(0.10)$ & 2.83 & $0.006^{*}$ \\
\hline & Gender & $0.00(0.18)$ & 0.02 & 0.99 & $\begin{array}{l}-0.03 \\
(0.18)\end{array}$ & -0.15 & 0.88 \\
\hline & Childhood FI & $-0.18(0.09)$ & -2.05 & $0.04^{*}$ & $\begin{array}{l}-0.17 \\
(0.09)\end{array}$ & -2.02 & $0.045^{*}$ \\
\hline & $\begin{array}{l}\text { Current FI * } \\
\text { Childhood FI }\end{array}$ & - & - & - & $\begin{array}{l}-0.18 \\
(0.08)\end{array}$ & -2.24 & $0.03^{*}$ \\
\hline
\end{tabular}

${ }^{*} p<0.05$ 


\section{Discussion}

It is well documented that $\mathrm{Fl}$ is associated with high body weight in Western women, but not men (Nettle et al., 2017; Townsend et al., 2001). However, the mechanisms by which such an association might come about have been little studied. One possibility is that experience of FI changes people's motivation to opportunistically consume energy-dense food when this is freely available. We investigated this possibility in a mock taste test where volunteers were given a pretext for eating as much or as little as they liked of three snack foods, and had their current and childhood FI measured.

We first considered only current $\mathrm{FI}$, in interaction with gender. For BMI, we found the pattern typical of previous studies in affluent populations: a positive association between current $\mathrm{FI}$ and BMI moderated by gender (a steeper slope for women than men), although the pattern was only statistically significant when using the USDA measure of current $\mathrm{FI}$, and not our novel AFI measure. For calorie consumption, we found only weak evidence in support of our predictions in these first analyses. There was a significant interaction between current $\mathrm{FI}$ and gender in predicting calorie consumption, and the slope was more positive for women than men. However, this pattern was only statistically significant using our novel AFI measure, not the USDA score. Moreover, even using the AFI measure, the significant interaction was driven as much by a negative relationship between $\mathrm{FI}$ and consumption in men (where we predicted a null association), as it was by a positive association between $\mathrm{FI}$ and consumption in women. For hedonic value of food, we found a simple association between current FI (by either measure) and liking for chocolate: more food-insecure individuals liked chocolate more, an effect not moderated by gender. There were however no associations between current $\mathrm{FI}$ and liking for either of our other two snack foods.

In a second set of analyses, we additionally considered the possible role of childhood $\mathrm{FI}$. These were exploratory analyses, since we had no clear predictions regarding whether childhood FI would have a separate additive effect, or interact with current FI and/or gender. For all three outcomes (BMI, calorie consumption, liking for chocolate), adding in childhood $\mathrm{Fl}$ improved model fit for one or both of the measures of current FI. In four of the five cases where it did so, there was a significant interaction between current FI and childhood FI. This suggests that childhood experience of FI might serve quite generally as a moderator of the impact of current FI on eating and weight. However, the mode of moderation was different for the different outcomes. For BMI, higher childhood FI made the association between current $\mathrm{FI}$ and BMI stronger, suggesting that childhood $\mathrm{FI}$ experiences might sensitize individuals to similar experiences later in life. For calorie consumption and liking for chocolate, the moderation was the other way around: higher childhood FI made the association between current FI and consumption/liking weaker. One way of interpreting this finding is that individuals who have experienced childhood FI behave as if food insecure in adulthood, regardless of whether they actually are or not. This interpretation would be compatible with previous descriptions of the impact of childhood poverty, deprivation or trauma on adult body weight and eating (Greenfield \& Marks, 2009; Hill et al., 2016; Olson et al., 2007). Our study goes beyond the prior research in specifically measuring and examining childhood $\mathrm{FI}$, as opposed to more general socioeconomic or psychosocial adversities in childhood. However, in view of the exploratory nature of the analyses and the contradictory directions of the findings, we view these result of the current study regarding childhood FI as indications of the need for future investigation. Why experiencing $\mathrm{FI}$ in childhood might enhance the effect of $\mathrm{FI}$ 
experience in adulthood for one outcome, body weight, whilst attenuating it for the linked outcomes of opportunistic calorie consumption and hedonic value of chocolate, is far from clear.

Tentative though the conclusions about childhood FI may be, the fact that we observe moderation by childhood FI does cast a somewhat different light on our main findings concerning current $\mathrm{FI}$ and calorie consumption. The evidence in this study for current $\mathrm{FI}$ predicting calorie consumption is weak when current $\mathrm{Fl}$ is considered without regard to childhood FI, being statistically significant only for one of the two current FI measures. However, in interaction with childhood FI, current FI significantly predicts consumption for both current FI measures. This suggests that effects of current FI can be masked because of moderation by childhood experience. This would mean that the moderate associations between current FI and women's body weight observed in the literature (Nettle et al., 2017) may be the amalgam of stronger associations in sub-groups with certain childhood experiences, and weaker or null associations in others. This is a potentially useful observation for the literature, and we suggest that measures of childhood experience could usefully be incorporated into study designs, even where the main study questions concern current FI.

The conceptual framework of our study is based on the idea that high BMI might be driven by higher consumption of energy-dense foods, which might in turn be driven by greater liking of those foods; and indeed, the associations with FI (for women) are all the same direction, higher $\mathrm{FI}$ predicting higher BMI, greater consumption, and greater liking for chocolate. However, the correlations in the dataset between liking of the foods, calorie consumption and $\mathrm{BMl}$ are very close to zero. Liking for a food is certainly not the only determinant of consumption (Brunstrom \& Rogers, 2009; Drewnowski, 1997; Finlayson et al., 2007), so the low correlation between liking and consumption is not in itself surprising. The mono-factorial hypothesis that variation in liking for foods (or energy-dense foods in particular) explains most of the individual variation in obesity is not well supported by evidence (Drewnowski, 1997). However, there is a case for a more subtle role of individual differences in hedonic response to particular foods in the pathway to weight gain in at least some individuals (Finlayson et al., 2007; Salbe, Delparigi, Pratley, Drewnowski, \& Tataranni, 2004). For example, variation in liking may inhibit flavour-specific satiety for particular types of food, or drive consumption in the absence of homeostatic need (see Nasser, 2001 for review). Thus, it would be possible for liking of energy-dense foods to be on the causal pathway liking $\mathrm{FI}$ to weight gain, without needing to claim that liking for energy-dense foods is the only or main determinant of body weight. However, our data to not directly demonstrate such a role: since liking for chocolate was not significantly related to calories consumed or body weight, it cannot formally be considered a mediator in this dataset.

An innovation of our study was the development of new questionnaires for adult FI (AFI) and $\mathrm{FI}$ in childhood (CFI). The adult scale broadened the focus of the USDA scale on financial constraints to obtaining food, and instead encompass the experience of irregularity in the food supply, regardless of the reasons for it. If there are psychological mechanisms that respond to irregular food intake, there is no reason to suspect that they are sensitive to the different reasons such irregularity occurs. Restriction imposed by non-financial constraints may have very similar consequences to financially-imposed restriction (Nettle et al., 2017; Polivy, 1996). Our new AFI measure was moderately correlated with the USDA scale. 
Moreover, it produced a much better distribution than the USDA scale, with a smaller mode at or near zero. This is probably related to the broader range of experiences that it asks about. However, we cannot make any strong claim that it had greater predictive utility than the USDA score. For consumption, it was the AFI measure that produced the significant association, whereas for BMI it was the USDA score. The parameter estimates for the two measures (which were directly comparable since variables were standardized for analysis) were very similar in both cases. The CFI questionnaire produced lower scores and a smaller range of variation than AFI. Participants reported that recall of the relevant experiences fairly easy, though less easy than for AFI. This may be because the present sample were mostly fairly young, and hence were recalling events of only a decade ago.

One limitation of the study is that almost all of the calorie consumption in the taste test was of the chocolate. This makes it impossible to establish whether any associations with $\mathrm{FI}$ are specific to chocolate: it is variation in consumption of chocolate that drives the statistical associations between $\mathrm{FI}$ and total consumption, but this may be because there is so much less variation in the consumption of the other foods. Interestingly, the only food for which liking was associated with FI was also chocolate. Chocolate was the only sweet food, and the hedonic value of and appetite for sweet foods have been implicated in weight gain following food restriction (Cabanac, Duclaux, \& Spector, 1971; Fantino, Baigts, Cabanac, \& Apfelbaum, 1983; Paradis \& Cabanac, 2008). However, since there was no replication of different kinds of sweet food, and chocolate differs from the other foods in other ways than just being sweet, our findings do not warrant any strong claims about appetite for sweet foods being specifically related to $\mathrm{Fl}$.

Ours is a correlational study, and from correlational data alone, it is not possible to make strong inferences about causality. Adult and childhood FI might causally impact eating and weight, but there are other possible pathways by which the associations we observe could come about. For example, a liking of or habitual consumption of energy-dense snack foods may cause differences in regularity of food intake, manifest as a higher FI score.

Alternatively, both FI and liking or consumption may be influenced by some unmeasured third variable. The only way to advance causal understanding in this area will be to find ways of experimentally manipulating FI. Recent research has shown that experimental manipulations of subjective social status can have an immediate causal impact on caloric consumption (Cardel et al., 2015; Cheon \& Hong, 2016). It is possible that these manipulations are effectively altering implicit or explicit feelings of $\mathrm{Fl}$. One of the definitive characteristics of low social status is more precarious access to resources. Thus, avenues for future research include determining whether these experimental manipulations alter perceived $\mathrm{Fl}$; whether changes in perceived $\mathrm{FI}$ mediate their effects on food consumption; and whether it is possible to manipulate FI directly by some means other than manipulating subjective social status. However, the experimental approach is not an available avenue for investigating the causal impact of $\mathrm{FI}$ in childhood. There are animal models where $\mathrm{FI}$ experiences during development can be experimentally manipulated (Andrews et al., 2015; Bloxham, Bateson, Bedford, Brilot, \& Nettle, 2014; Remmers \& Delemarre-van de Waal, 2011). For childhood experience of $\mathrm{FI}$ in humans, which our findings suggest could be important, we are effectively restricted to correlational epidemiological methods.

In conclusion, by presenting volunteers who also completed FI questionnaires with a standardized opportunity to consume energy-dense snack food, our study shed some light 
on the pathways by which FI may lead to high body weight. Higher-FI women consumed more calories, and higher-FI participants of both sexes liked chocolate more. We also found exploratory evidence suggesting that childhood $\mathrm{Fl}$, which has not been specifically measured before, may moderate the individual's response to experiences of $\mathrm{Fl}$ in adulthood.

\section{Acknowledgements}

This project has received funding from the European Research Council (ERC) under the European Union's Horizon 2020 research and innovation programme (grant agreement No AdG 666669, COMSTAR). 


\section{Appendix: Food insecurity questionnaires}

Instructions:

Childhood food insecurity: Please think back to a period before you were 12 years old when answering the following questions.

Adult food insecurity: Please think about the past year when answering the following questions.

All questions have a yes/no response format.

1. Did you have a consistent dinnertime?

2. Did you usually feel full after meals?

3. Did you worry about food supplies running out?

4. Did you ever not eat for a whole day?

5. Were you ever unsure where your next meal would come from?

6. Did you ever find that good quality food was not available?

7. Were your cupboards always full?

8. Were your meals mainly made up from cheap foods?

9. Did you ever miss an evening meal?

10. Did you regularly eat food that you liked?

11. Were you sometimes unsure about the time of your next meal?

12. Did you usually have dessert after your evening meal?

13. Did you overall have a healthy diet?

14. Did you ever miss lunch?

15. Did you ever go to sleep hungry?

16. Could you afford to eat balanced meals?

17. Did you struggle to have three meals on some days?

18. Were your meals a similar size from day to day?

19. Were you ever hungry but didn't eat because there was not money to buy food?

20. Did you ever miss breakfast? 


\section{References}

Adams, E. J., Grummer-strawn, L., \& Chavez, G. (2003). Food Insecurity Is Associated with Increased Risk of Obesity in California. Journal of Nutrition, 1070-1074.

Anderson, S. A. (1990). Core indicators of nutritional state for difficult-to-sample populations. The Journal Of Nutrition, 120 Suppl, 1559-1600.

Andrews, C., Viviani, J., Egan, E., Bedford, T., Brilot, B., Nettle, D., \& Bateson, M. (2015). Early-life adversity increases foraging and information gathering in European starlings, Sturnus vulgaris. Animal Behaviour, 109, 123-32. http://doi.org/10.1016/j.anbehav.2015.08.009

Bickel, G., Nord, M., Price, C., Hamilton, W., \& Cook, J. (2000). Measuring food security in the United States: Guide to measuring household food security. Washington (DC): USDA.

Bickel, G., Nord, M., Price, C., Hamilton, W., Cook, J., \& U.S. Department of Agriculture Food and Nutrition Service. (2000). h. Washington (DC): USDA.

Bloxham, L., Bateson, M., Bedford, T., Brilot, B., \& Nettle, D. (2014). The memory of hunger: developmental plasticity of dietary selectivity in the European starling, Sturnus vulgaris. Animal Behaviour, 91, 33-40. http://doi.org/10.1016/j.anbehav.2014.02.025

Brunstrom, J. M., \& Rogers, P. J. (2009). How many calories are on our plate expected fullness, not liking, determines meal-size selection. Obesity, 17(10), 1884-1890. http://doi.org/10.1038/oby.2009.201

Cabanac, M., Duclaux, R., \& Spector, N. H. (1971). Sensory feedback in regulation of body weight: Is there a ponderostat? Nature, 229(5280), 125-127. http://doi.org/10.1038/229125a0

Cardel, M. I., Johnson, S. L., Beck, J., Dhurandhar, E., Keita, A. D., Tomczik, A. C., ... Allison, D. B. (2015). The effects of experimentally manipulated social status on acute eating behavior: A randomized, crossover pilot study. Physiology and Behavior, 162, 93-101. http://doi.org/10.1016/j.physbeh.2016.04.024

Cheon, B. K., \& Hong, Y.-Y. (2016). Mere experience of low subjective socioeconomic status stimulates appetite and food intake. Proceedings of the National Academy of Sciences, 201607330. http://doi.org/10.1073/pnas.1607330114

Crawford, P. B., \& Webb, K. L. (2011). Unraveling the paradox of concurrent food insecurity and obesity. American Journal of Preventive Medicine, 40(2), 274-275.

http://doi.org/10.1016/j.amepre.2010.11.003

Dinour, L. M., Bergen, D., \& Yeh, M. C. (2007). The Food Insecurity-Obesity Paradox: A Review of the Literature and the Role Food Stamps May Play. Journal of the American Dietetic Association, 107(11), 1952-1961. http://doi.org/10.1016/j.jada.2007.08.006

Drewnowski, A. (1997). Taste Preferences and Food Intake. Annual Review of Nutrition, 17, 237-253. http://doi.org/10.1146/annurev.nutr.17.1.237

Ekman, J. B., \& Hake, M. K. (1990). Monitoring starvation risk: Adjustments of body reserves in Greenfinches (Carduelis Chloris L.) during periods of unpredictable foraging success. 
Behavioral Ecology, 1(1), 62-67. http://doi.org/10.1093/beheco/1.1.62

Fantino, M., Baigts, F., Cabanac, M., \& Apfelbaum, M. (1983). Effects of an overfeeding regimen - the affective component of the sweet sensation. Appetite, 4(3), 155-164. http://doi.org/10.1016/S0195-6663(83)80028-2

Finlayson, G., King, N., \& Blundell, J. E. (2007). Liking vs. wanting food: Importance for human appetite control and weight regulation. Neuroscience and Biobehavioral Reviews, 31(7), 987-1002. http://doi.org/10.1016/j.neubiorev.2007.03.004

Greenfield, E. A., \& Marks, N. F. (2009). Violence from parents in childhood and obesity in adulthood: using food in response to stress as a mediator of risk. Social Science \& Medicine (1982), 68(5), 791-8. http://doi.org/10.1016/j.socscimed.2008.12.004

Griskevicius, V., Tybur, J. M., Delton, A. W., \& Robertson, T. E. (2011). The influence of mortality and socioeconomic status on risk and delayed rewards: a life history theory approach. Journal of Personality and Social Psychology, 100(6), 1015-1026. http://doi.org/10.1037/a0022403

Gundersen, C., Kreider, B., \& Pepper, J. (2011). The economics of food insecurity in the United States. Applied Economic Perspectives and Policy, 33(3), 281-303. http://doi.org/10.1093/aepp/ppr022

Hanson, K. L., Sobal, J., \& Frongillo, E. a. (2007). Gender and marital status clarify associations between food insecurity and body weight. The Journal of Nutrition, 137(6), 1460-1465.

Higginson, A. D., McNamara, J. M., \& Houston, A. I. (2016). Fatness and fitness: Exposing the logic of evolutionary explanations for obesity. Proceedings of the Royal Society $B$ : Biological Sciences, 283, 20152443.

Hill, S. E., Prokosch, M. L., DelPriore, D. J., Griskevicius, V., \& Kramer, A. (2016). Low Childhood Socioeconomic Status Promotes Eating in the Absence of Energy Need. Psychological Science. http://doi.org/10.1017/CBO9781107415324.004

Kendall, A., Olson, C. M., \& Frongillo, E. A. (1996). Relationship of hunger and food insecurity to food availability and consumption. Journal of the American Dietetic Association. http://doi.org/10.1016/S0002-8223(96)00271-4

Li, X., Cope, M. B., Johnson, M. S., Smith, D. L., \& Nagy, T. R. (2010). Mild calorie restriction induces fat accumulation in female C57BL/6J mice. Obesity, 18, 456-462. http://doi.org/10.1038/oby.2009.312

Lima, S. L. (1986). Predation risk and unpredictable feeding conditions : determinants of body mass in birds. Ecology, 67(2), 377-385.

Martin-Fernandez, J., Caillavet, F., Lhuissier, A., \& Chauvin, P. (2014). Food insecurity, a determinant of obesity? - An analysis from a population-based survey in the Paris metropolitan area, 2010. Obesity Facts, 7(2), 120-129. http://doi.org/10.1159/000362343

Nasser, J. (2001). Taste, food intake and obesity. Obesity Reviews, 2(4), 213-218. http://doi.org/10.1046/j.1467-789X.2001.00039.x

Nettle, D., Andrews, C., \& Bateson, M. (2017). Food insecurity as a driver of obesity in 
humans: The insurance hypothesis. Behavioral and Brain Sciences, 40, e105.

http://doi.org/10.1017/S0140525X16000947

Olson, C. M., Bove, C. F., \& Miller, E. O. (2007). Growing up poor: Long-term implications for eating patterns and body weight. Appetite, 49(1), 198-207.

http://doi.org/10.1016/j.appet.2007.01.012

Paradis, S., \& Cabanac, M. (2008). Dieting and food choice in grocery shopping. Physiology and Behavior, 93(4-5), 1030-1032. http://doi.org/10.1016/j.physbeh.2008.01.014

Polivy, J. (1996). Psychological consequences of food restriction. Journal of the American Dietetic Association. http://doi.org/10.1016/S0002-8223(96)00161-7

R Core Team. (2016). R: A language and environment for statistical computing.

Remmers, F., \& Delemarre-van de Waal, H. A. (2011). Developmental programming of energy balance and its hypothalamic regulation. Endocrine Reviews, 32(2), 272-311. http://doi.org/10.1210/er.2009-0028

Salbe, A. D., Delparigi, A., Pratley, R. E., Drewnowski, A., \& Tataranni, P. A. (2004). Taste preferences and body weight changes in an obesity-prone, (February), 372-378.

Sharkey, J. R., Nalty, C., Johnson, C. M., \& Dean, W. R. (2012). Children's very low food security is associated with increased dietary intakes in energy, fat, and added sugar among Mexican-origin children (6-11 y) in Texas border Colonias. BMC Pediatrics, 12(1), 16. http://doi.org/10.1186/1471-2431-12-16

Tanumihardjo, S. a., Anderson, C., Kaufer-Horwitz, M., Bode, L., Emenaker, N. J., Haqq, A. M., ... Stadler, D. D. (2007). Poverty, Obesity, and Malnutrition: An International Perspective Recognizing the Paradox. Journal of the American Dietetic Association, 107(11), 19661972. http://doi.org/10.1016/j.jada.2007.08.007

Townsend, M. S., Peerson, J., Love, B., Achterberg, C., \& Murphy, S. P. (2001). Food insecurity is positively related to overweight in women. The Journal of Nutrition, 131(6), 1738-1745.

Wang, X. T., \& Dvorak, R. D. (2010). Sweet future: Fluctuating blood glucose levels affect future discounting. Psychological Science, 21(2), 183-188. http://doi.org/10.1177/0956797609358096

Wilson, J. F., \& Cantor, M. B. (1987). An animal model of excessive eating: Schedule-induced hyperphagia in food-satiated rats. Journal of the Experimental Analysis of Behavior, 47, 335-46.

Witter, M., \& Swaddle, J. P. (1995). Dominance, competition, and energetic reserves in the European starling, Sturnus vulgaris. Behavioral Ecology, 6, 343-348. http://doi.org/10.1093/beheco/6.3.343 